\title{
Abnormal blood viscosity and haemostasis in long-standing retinal vein occlusion
}

\author{
GRAHAM E. TROPE, ${ }^{*}$ GORDON D. O. LOWE, BRENDA M. MCARDLE, \\ JESSIE T. DOUGLAS, CHARLES D. FORBES, COLIN M. PRENTICE, AND \\ WALLACE S. FOULDS* \\ From the *Tennent Institute of Ophthalmology, Western Infirmary, Glasgow, and the University Department of \\ Medicine, Royal Infirmary, Glasgow
}

SUMMARY Blood viscosity and several haemostatic factors were measured in 42 patients with long-standing retinal vein occlusion and 33 control subjects. Blood viscosity, haematocrit, plasma viscosity, fibrinogen, fibrinopeptide $A$, and beta-thromboglobulin were increased in the 20 subjects with capillary nonperfusion or new vessels, but not in the 22 subjects without these complications. Patients with nonperfusion or new vessels also had a lower platelet count than patients without complications. Increased levels of factor VIII antigen and decreased levels of antithrombin III were found in the retinal vein occlusion group as a whole. These findings suggest that blood viscosity, platelets, and coagulation may be involved in retinal vein occlusion and its vascular complications.

Retinal vein occlusion has several well recognised clinical associations, including hypertension, hyperlipidaemia, diabetes, polycythaemia, and hypergammaglobulinaemia.' 'Since the latter 2 disorders cause increased blood viscosity, which slows retinal blood flow, ${ }^{2}$ a causal role for increased viscosity in retinal vein occlusion has been postulated. Two studies of blood viscosity in patients with recent retinal vein occlusion have been reported. ${ }^{13}$ Ring $e t$ $a l .^{3}$ found increased blood viscosity in patients with capillary nonperfusion as shown by fluorescein angiography and suggested that increased viscosity might be a causal factor in the development of capillary nonperfusion as well as a causal factor in retinal vein occlusion. McGrath et al. ${ }^{1}$ found increased viscosity in $53 \%$ of 79 patients with recent retinal vein occlusion, but did not relate viscosity to capillary nonperfusion. In both these studies increases in haematocrit, plasma fibrinogen, and immunoglobulins were found, which could have contributed to the hyperviscosity.

In both these studies ${ }^{13}$ viscosity was measured in the acute stage of venous occlusion: no studies in long-standing vein occlusion have been reported. The possibility exists, therefore, that the increase in viscosity might have been a result of the acute vascular

Correspondence to Dr Graham E. Trope, FRCS, Tennent Institute of Ophthalmology, Western Infirmary, Glasgow G11 6NT. event. For example, the plasma fibrinogen level is known to increase in a variety of acute illnesses. ${ }^{4}$ Furthermore in both studies patients with retinal vein occlusion, half of whom had hypertension, were compared with control subjects without hypertension. Since there is now good evidence that increased levels of blood viscosity, haematocrit, and fibrinogen are found in subjects with hypertension, ${ }^{5}$ the increased viscosity reported in both studies might have been associated with hypertension rather than with retinal vein occlusion. To clarify the relationship of blood viscosity to retinal vein occlusion we have measured viscosity and its major determinants in a series of patients with long-standing retinal vein occlusion, compared with controls matched for blood pressure, diabetes, age, sex, and smoking habit. In view of the report ${ }^{3}$ that viscosity was related to capillary nonperfusion at fluorescein angiography in acute venous occlusion, we have related viscosity to the presence of angiographically demonstrated capillary nonperfusion and its sequel, neovascularisation.

Apart from increased viscosity, abnormalities of blood haemostatic factors (blood coagulation, fibrinolysis, and platelet behaviour) might conceivably play a role in retinal vein occlusion or its ischaemic complications, especially if thrombosis contributes to vascular occlusion. In recent years several specific tests of haemostatic behaviour have 
become available, and several abnormalities have been associated with arterial and venous occlusions elsewhere in the body. ${ }^{4}$ We therefore measured several of these haemostatic factors as well as blood viscosity in retinal vein occlusion.

\section{Subjects and methods}

Forty-two unselected patients with retinal vein occlusion who were attending ophthalmology departments in Glasgow hospitals were studied after informed consent. All were in the chronic phase (3 months to 3 years since onset of symptoms). All underwent full ophthalmological and medical assessment, including fluorescein angiography and screening for hypertension and diabetes, which were treated appropriately. Thirty-three control subjects were selected from patients attending hypertension clinics and patients admitted for elective surgery. This group was matched for age, sex, smoking habit, diabetes, hypertension, and treatment of hypertension with the retinal vein occlusion group. All subjects were ambulant and none had any acute illness.

Venous blood was sampled between 10 and 11 a.m., after 10 minutes' rest, from a forearm vein with a 19 gauge 'butterfly' needle (Abbott) without a tourniquet. Blood was anticoagulated with edetic acid (EDTA, $1.5 \mathrm{mg} / \mathrm{ml}$ ) for viscosity studies, which were performed within 2 hours of venepuncture. Whole blood viscosity was measured at a high shear rate $\left(94 \mathrm{~s}^{-1}\right)$ and at a low shear rate $\left(0.94 \mathrm{~s}^{-1}\right)$ in a Contraves LS 30 rotational viscometer, at temperature $37^{\circ} \mathrm{C}$. Haematocrit (Hawksley microhaematocrit, $13000 \mathrm{~g}$ for 5 minutes), plasma viscosity (CoulterHarkness capillary viscometer, $25^{\circ} \mathrm{C}$ ), and platelet count (Coulter Thrombocounter) were measured on the same sample. Serum immunoglobulins were measured by automated immunoprecipitation.

Blood was anticoagulated with trisodium citrate
$(0 \cdot 129 \mathrm{M}, 9: 1 \mathrm{v}: \mathrm{v})$ for measurement of plasma fibrinogen, factor VIII activity, factor VIII antigen, antithrombin III activity, plasminogen activity, fast antiplasmin activity, and alpha-2-macroglobulin antigen, as previously described. ${ }^{6}$ Serum fibrin degradation products were assayed by the Wellcome FDP kit. Plasma levels of beta-thromboglobulin and fibrinopeptide A were measured by radioimmunoassay as previously described, ${ }^{7}$ except that prostaglandin $E_{1}$ (Upjohn) was added to the sample tubes for beta-thromboglobulin assay in order to minimise platelet release in vitro.

Statistical analysis of differences between groups was performed by the 2-tailed Student's $t$-test and Mann-Whitney U test as appropriate.

\section{Results}

\section{CLINICAL VARIABLES AND IMMUNOGLOBULINS}

(Table 1)

Twenty subjects with retinal vein occlusion had capillary nonperfusion and/or neovascularisation at

Table 1 Clinical features and immunoglobulins in patient groups

\begin{tabular}{llll}
\hline & \multicolumn{2}{l}{ Retinal vein occlusion } & \multirow{2}{*}{ Controls } \\
\cline { 2 - 3 } & Group I & Group 2 & \\
\hline Number & 20 & 22 & 33 \\
Age (years) & $67 \cdot 6($ SEM $2 \cdot 1)$ & $66 \cdot 6(2 \cdot 4)$ & $66 \cdot 7(2 \cdot 0)$ \\
Males & 13 & 8 & 17 \\
Smokers & 2 & 8 & 9 \\
Hypertension & 13 & 9 & 17 \\
Diabetes & 1 & 2 & 2 \\
Site: central & 10 & 14 & - \\
$\quad$ branch & 8 & 8 & - \\
$\quad$ both & 2 & 0 & - \\
Abnormal & $7 / 12$ & $7 / 16$ & - \\
immunoglobulins & & & \\
\hline
\end{tabular}

SEM: standard error of mean in parentheses.

Table 2 Blood viscosity and its determinants in patient groups

\begin{tabular}{|c|c|c|c|c|c|}
\hline & Group I & Group 2 & Total RVO & Controls & $\begin{array}{l}\text { Group 1 } \\
\text { vs. } \\
\text { Group } 2\end{array}$ \\
\hline $\begin{array}{l}\text { Blood viscosity (mPa s): } \\
0 \cdot 94 \mathrm{~s}^{-1} \\
\text { corrected } \\
94 \mathrm{~s}^{-1} \\
\text { corrected }\end{array}$ & $\begin{array}{l}23 \cdot 2(1 \cdot 6)^{* *} \\
22 \cdot 8(0 \cdot 8)^{* *} \\
6 \cdot 54(0 \cdot 30)^{* *} \\
6 \cdot 46(0 \cdot 17)^{* *}\end{array}$ & $\begin{array}{l}17 \cdot 2(0 \cdot 6) \\
19 \cdot 3(0 \cdot 4) \\
5 \cdot 37(0 \cdot 17) \\
5 \cdot 68(0 \cdot 12)\end{array}$ & $\begin{array}{l}20 \cdot 1(0 \cdot 9)^{*} \\
21 \cdot 0(0 \cdot 5) \\
5 \cdot 93(0 \cdot 19)^{*} \\
6 \cdot 05(0 \cdot 12)\end{array}$ & $\begin{array}{l}17 \cdot 0(0 \cdot 8) \\
19 \cdot 8(0 \cdot 5) \\
5 \cdot 36(0 \cdot 15) \\
5 \cdot 81(0 \cdot 12)\end{array}$ & $\begin{array}{l}* * \\
* * \\
* * \\
* *\end{array}$ \\
\hline Haematocrit & $0 \cdot 450(0 \cdot 010)^{* *}$ & $0 \cdot 425(0 \cdot 008)$ & $0.436(0.006)^{*}$ & $0.414(0.008) \cdot$ & \\
\hline $\begin{array}{l}\text { Plasma viscosity (mPa s) } \\
\text { Fibrinogen }(\mathrm{g} / 1)\end{array}$ & $\begin{array}{l}1 \cdot 88(0 \cdot 03)^{* *} \\
3 \cdot 67(0 \cdot 20)^{* *}\end{array}$ & $\begin{array}{l}1 \cdot 79(0 \cdot 03) \\
2 \cdot 79(0 \cdot 15)\end{array}$ & $\begin{array}{l}1 \cdot 83(0 \cdot 02)^{*} \\
3 \cdot 19(0 \cdot 14)\end{array}$ & $\begin{array}{l}1.77(0 \cdot 03) \\
2.92(0 \cdot 14)\end{array}$ & $\stackrel{*}{* *}$ \\
\hline
\end{tabular}

Results are given as mean with SEM in brackets. Asterisks indicate significant differences in RVO patients compared with controls. ${ }^{*} \mathrm{p}<0 \cdot 05$; ${ }^{* *} \mathrm{p}<0 \cdot 01$. RVO $=$ retinal vein occlusion. $\mathrm{mPa} \mathrm{s}=$ millipascal second. SI conversion: 1 millipascal second $=1$ centipoise. 
Table 3 Haemostatic factors in patient groups

\begin{tabular}{|c|c|c|c|c|c|}
\hline & Group 1 & Group 2 & Total RVO & Controls & $\begin{array}{l}\text { Group 1 } \\
\text { vs. } \\
\text { Group } 2\end{array}$ \\
\hline Antithrombin III (U/ml) & $10 \cdot 7(0 \cdot 8)^{*}$ & $9 \cdot 2(0 \cdot 6)^{* *}$ & $9 \cdot 9(0 \cdot 5)^{* *}$ & $12 \cdot 7(0 \cdot 5)$ & \\
\hline Factor VIII activity $(\mathrm{U} / \mathrm{ml})$ & $1 \cdot 67(0 \cdot 27)$ & $1 \cdot 46(0 \cdot 15)$ & $1 \cdot 56(0 \cdot 15)$ & $1 \cdot 56(0 \cdot 10)$ & \\
\hline Factor VIII antigen $(\mathrm{U} / \mathrm{ml})$ & $1.80(0.29)$ & $1 \cdot 54(0 \cdot 17)$ & $1.67(0.17)^{*}$ & $1 \cdot 22(0 \cdot 14)$ & \\
\hline Fibrinopeptide A (ng/ml) & $7 \cdot 2(2 \cdot 8)^{*}$ & $1 \cdot 3(0 \cdot 2)$ & $4 \cdot 1(1 \cdot 4)$ & $1 \cdot 0(0 \cdot 3)$ & * \\
\hline Platelet count $\left(\times 10^{9} / 1\right)$ & $184(11)$ & $223(13)$ & $205(9)$ & $215(10)$ & * \\
\hline Beta-thromboglobulin (ng/ml) & $43(6)^{*}$ & $32(4)$ & $37(4)^{*}$ & $27(2)$ & \\
\hline Plasminogen $(\mathrm{CU} / \mathrm{ml})$ & $3 \cdot 0(0 \cdot 2)$ & $2 \cdot 9(0 \cdot 2)$ & $2 \cdot 9(0 \cdot 1)$ & $2 \cdot 6(0 \cdot 2)$ & \\
\hline Fast antiplasmin $(\mathrm{U} / \mathrm{ml})$ & $1.9(0.3)$ & $2 \cdot 1(0 \cdot 3)$ & $2 \cdot 0(0 \cdot 2)$ & $2 \cdot 0(0 \cdot 2)$ & \\
\hline Alpha $_{2}$ macroglobulin (\% normal) & $110(10)$ & $99(6)$ & $104(5)$ & $91(5)$ & \\
\hline Fibrin degradation products $(\mu \mathrm{g} / \mathrm{ml})$ & $4 \cdot 8(0 \cdot 8)$ & $4.5(0.5)$ & $4 \cdot 6(0 \cdot 5)$ & $5 \cdot 4(0 \cdot 7)$ & \\
\hline
\end{tabular}

Results are given as mean with SEM in brackets. Asterisks indicate differences in RVO patients compared with controls, ${ }^{*} p<0 \cdot 05 ;{ }^{* *} p<0 \cdot 01$. RVO = retinal vein occlusion. $\mathrm{CU}=$ casein units.

fluorescein angiography (group 1) and 22 did not (group 2). 52\% of patients had hypertension and $52 \%$ had increased levels of at least one class of immunoglobulin, in the following order of frequency: IgM, $\operatorname{IgG}, \operatorname{IgA}$. No patient with raised immunoglobulin had a definite haemoproliferative or connective tissue disorder. Table 1 shows that there were no significant differences in clinical factors or immunoglobulin abnormalities between group 1 and group 2 .

\section{BLOOD VIscosity (Table 2)}

Blood viscosity was significantly higher in the whole retinal vein occlusion group than in the controls, but the increase in viscosity was confined to patients in group 1 (capillary nonperfusion and/or new vessels), who had significantly higher viscosity than group 2 or the control group. Mean blood viscosity was $36 \%$ higher than that of controls when measured at the low shear rate $\left(0.94 \mathrm{~s}^{-1}\right)$ and $22 \%$ higher when measured at the high shear rate $\left(94 \mathrm{~s}^{-1}\right)$. Mean blood viscosity in group 2 was similar to that in the control group. In part the increased viscosity in group 1 was associated with a significant increase in the haematocrit. However, when blood viscosity was corrected to a standard haematocrit of 0.45 by means of regression equations of viscosity and haematocrit, ${ }^{3}$ blood viscosity at both shear rates was still significantly higher in group 1 . This was associated with a significant increase in plasma viscosity, which was in turn associated with a significantly higher plasma fibrinogen level. The increase in plasma viscosity was unrelated to increased levels of immunoglobulins, partly because subjects with raised immunoglobulins tended to have lower fibrinogen levels than subjects with normal immunoglobulins.

HAEMOSTATIC FACTORS (Table 3)

Plasma levels of antithrombin III were significantly lower in both groups of subjects with retinal vein occlusion than in the controls. Mean plasma factor VIII antigen was higher in the total group of retinal vein occlusion subjects than in controls: the highest levels were found in group 1 . Subjects in group 1 also had higher levels of fibrinopeptide $A$ and betathromboglobulin than the controls and a lower platelet count than group 2. Levels of other haemostatic factors did not show significant differences between groups.

\section{Discussion}

We have shown that patients with long-standing retinal vein occlusion who have capillary nonperfusion and/or new vessel formation (group 1) have (a) increased blood viscosity, due to increased levels of haematocrit, plasma viscosity and fibrinogen; and $(b)$ abnormalities of 5 tests of blood coagulation and platelet behaviour (antithrombin III, factor VIII antigen, fibrinopeptide $\mathrm{A}$, beta-thromboglobulin, and platelet count). In patients with retinal vein occlusion but without ischaemic complications (group 2) the only abnormality was a lower level of antithrombin III. The significance of these findings will be discussed in turn.

\section{BLOOD VISCOSITY}

We have confirmed 2 previous reports that patients with retinal vein occlusion have increased blood viscosity. ${ }^{13}$ Since our patients were studied in the chronic phase, and since our control group was matched for hypertension, it appears that the increase in viscosity is neither an acute-phase reaction to vascular occlusion nor an association with underlying hypertension.

One previous study ${ }^{3}$ found increased blood viscosity only in patients with capillary nonperfusion on fluorescein angiography. While we have found a significant increase in blood viscosity in our total group 
of patients with retinal vein occlusion, further analysis indicated that the increased viscosity was confined to those patients with capillary nonperfusion or its sequel, neovascularisation (group 1, Table 2). The increase in blood viscosity in patients with retinal ischaemia is very similar in the 2 studies. The previous study $^{3}$ found a mean increase of about $35 \%$ when viscosity was measured at a shear rate of $0.77 \mathrm{~s}^{-1}$; in the present study the mean increase in viscosity was $36 \%$, measured at a similar shear rate of $0.94 \mathrm{~s}^{-1}$. It therefore appears that patients with retinal vein occlusion and capillary nonperfusion have a significant increase $(p<0.005)$ in blood viscosity both in the acute phase ${ }^{3}$ and in the chronic phase (present study).

Blood viscosity is determined partly by the haematocrit and partly by the plasma proteins, which influence plasma viscosity and red cell aggregation. ${ }^{8}$ We found that the increased blood viscosity in group 1 was partly due to a small but statistically significant increase in haematocrit, but the increased haematocrit did not account for more than about half of the increase in viscosity: correction of blood viscosity to a standard haematocrit $(0 \cdot 45)$ still showed a significant increase in group 1 . This was associated with a significant increase in plasma viscosity, which correlated with an increased level of plasma fibrinogen. Thus the increased viscosity in group 1 appears to be due partly to a higher haematocrit and partly to a raised level of plasma fibrinogen. The results of the previous study ${ }^{3}$ are similar with regard to blood viscosity, haematocrit, and corrected blood viscosity. However, while these authors ${ }^{3}$ found significant increases in plasma viscosity and fibrinogen in patients with retinal vein occlusion compared with controls, neither of these 2 variables was related to capillary nonperfusion. One explanation for these different results may be that in the previous study ${ }^{3}$ of patients with acute vein occlusion variable acute-phase increases in plasma viscosity and fibrinogen may have obscured their relationship to capillary nonperfusion.

We found a high prevalence of raised immunoglobulins in patients with retinal vein occlusion, in agreement with previous studies. ${ }^{13}$ It has been suggested $^{1}$ that these increases might contribute to the hyperviscosity in retinal vein occlusion. Our data, however, show no correlation between viscosity and raised immunoglobulins. Patients in group 2 had the same prevalence of raised immunoglobulins as patients in group 1 but no increase in plasma or blood viscosity. In fact patients with raised immunoglobulins tended to have lower levels of plasma viscosity, partly owing to a tendency to lower fibrinogen levels. On the other hand it seems reasonable to assume that the haemorrhagic retinopathy in patients with very high levels of paraproteins (myeloma, macroglobulinaemia) may be related to their effect on viscosity. No such patients were encountered in the present series. Increased viscosity in group 1 could not be explained by significant differences in clinical variables (Table 1).

It has been suggested that increased blood viscosity might play a role in retinal venous occlusion. ${ }^{13}$ There is circumstantial evidence supporting this possibility. Increased blood viscosity has been associated with arterial and venous thrombosis elsewhere in the body. ${ }^{8}$ The defibrinating agent ancrod lowers the plasma fibrinogen level and hence plasma and blood viscosity: it has been shown to reduce the incidence and extent of leg vein thrombosis after surgery. ${ }^{9}$ Increased blood viscosity is associated with decreased rate of retinal blood flow. ${ }^{2}$ Increased viscosity in several haematological disorders is associated with retinal venous abnormalities, which resolve following reduction of blood viscosity; retinal vein occlusion is also a recognised complication of these disorders. ${ }^{8}$ In partial venous occlusion, venous flow rates may fall, resulting in low shear rates which allow local increases in blood viscosity due to red cell aggregation.

These increases in red cell aggregation and viscosity under low-shear conditions are strongly favoured by increases in haematocrit and fibrinogen, ${ }^{8}$ and might cause a 'rheological obstruction' which completes a partial, anatomical vein occlusion. ${ }^{3}$ If this were so, improvement in retinal blood flow might be achieved by a reduction in blood viscosity. There is some evidence that vision might be improved in some patients with retinal vein occlusion by treatment with ancrod or streptokinase, which lower plasma fibrinogen and hence viscosity ${ }^{10}{ }^{11}$ or by haemodilution, which lowers the haematocrit and hence viscosity. ${ }^{12}$

While it is possible that increased viscosity might promote retinal vein occlusion, increased viscosity was found only in patients with capillary nonperfusion or new vessels. This finding is consistent with a previous study ${ }^{3}$ and with the suggestion ${ }^{3}$ that increased viscosity might be one factor causing circulatory stagnation in areas of nonperfusion. It is relevant that we have previously reported high blood viscosity in diabetics with proliferative retinopathy compared with diabetics without this complication. ${ }^{13}$ Neovascularisation is associated with capillary nonperfusion ${ }^{14}$ and presumably arises as a response to local ischaemia. In view of these findings studies of blood viscosity reduction in patients with acute retinal vein occlusion seem justified. If increased viscosity is a factor promoting ischaemia, then reducing viscosity to lownormal levels for several months after the onset of venous occlusion might prevent retinal ischaemia and neovascularisation, with its complications of neovascular glaucoma or vitreous haemorrhage and its sequelae. 


\section{HAEMOSTATIC FACTORS}

Among haemostatic factors the most consistent finding in retinal vein occlusion was a decrease in plasma levels of antithrombin III, the major inhibitor of blood coagulation. A similar decrease in antithrombin III levels in acute retinal vein occlusion has recently been reported. ${ }^{15}$ The decrease was significant in both groups of patients with retinal vein occlusion, and was the only significant haematological abnormality in patients without capillary nonperfusion or new vessels (group 2). Whether the decrease in antithrombin III might promote retinal vein thrombosis is not known. Deficiency of antithrombin III may be familial, when it is associated with increased risk of venous thrombosis in other parts of the body. ${ }^{16} \mathrm{In}$ terestingly, a review of reported families does not mention retinal vein occlusion as a complication of congenital antithrombin III deficiency. ${ }^{16}$ Since retinal vein occlusion tends to affect older age groups, it is possible that insufficient numbers of older patients with antithrombin III deficiency have been studied to determine whether or not there is an increased incidence of retinal thrombosis.

The increased plasma fibrinogen level in group 1 has already been discussed as a determinant of increased viscosity. Whether or not increased fibrinogen levels favour thrombosis is uncertain, ${ }^{4}$ but we have shown that patients in group 1 have increased levels of fibrinopeptide $A$, which as the first peptide split from the fibrinogen molecule by thrombin is a sensitive measure of activation of blood coagulation. ${ }^{17}$ This suggests that activation of blood coagulation is present in some subjects with capillary nonperfusion or new vessel formation.

We found an increased level of factor VIII antigen in retinal vein occlusion. This again has recently been reported in acute retinal vein occlusion. ${ }^{15}$ Patients in group 1 had the highest levels of factor VIII antigen. The factor VIII molecule is released from vascular endothelium, and has its coagulant (antihaemophilic) activity conferred at an unknown site. Increased factor VIII levels are found in conditions associated with endothelial damage or proliferation. Of particular interest is the increase described in diabetics with proliferative retinopathy. ${ }^{18}$ Our finding of increased factor VIII antigen in patients with ischaemic/proliferative retinopathy following retinal vein occlusion suggests that increased factor VIII antigen is common to both types of ischaemic/proliferative retinopathy - diabetic and postvenous occlusion. While the increase could be a result of vascular damage, factor VIII antigen promotes platelet adhesion to vascular endothelium, ${ }^{19}$ so that increased levels might favour platelet deposition on the vessel wall.

Platelet activation and consumption in diabetic retinopathy is suggested by the lower platelet count in diabetics ${ }^{20}$ and by increased plasma levels of the platelet-specific protein, beta-thromboglobulin, in diabetics with retinopathy, especially proliferative retinopathy. ${ }^{21}$ Our finding of a reduced platelet count and increased plasma levels of beta-thromboglobulin in patients in group 1 suggests that platelet consumption and activation is also a feature of ischaemic/proliferative retinopathy after retinal vein occlusion. Increased platelet coagulant activities have been described in acute retinal vein occlusion, ${ }^{22}$ as has increased platelet aggregability in impending central vein occlusion. ${ }^{23}$ Taken together these findings suggest that platelets may be involved in retinal vein occlusion and its complications.

Thrombosis may be favoured not only by increased blood coagulation or platelet activation but also by decreased fibrinolysis. Impaired fibrinolysis has been described in acute retinal vein occlusion. ${ }^{15}$ For logistic reasons we were unable to measure fibrinolytic activity in this study, but we have measured plasma levels of plasminogen (the precursor of the fibrinolytic enzyme, plasmin), rapid antiplasmin and alpha-2macroglobulin (the major inhibitors of plasmin), and fibrin degradation products. All these variables were normal in both groups of patients with retinal vein occlusion.

In conclusion, we have shown several abnormalities in long-standing retinal vein occlusion which suggest possible involvement of blood viscosity and haemostasis. Decreased antithrombin III was found in some patients with or without ischaemic complications. Whether this abnormality could promote retinal vein thrombosis and occlusion is not known, but we suggest that patients with retinal vein occlusion might be screened for congenital deficiency of antithrombin III, and anticoagulant therapy be considered in subjects with very low levels. ${ }^{16}$ Potentially the most significant findings relate to patients with ischaemic complications (group 1). In common with a previous study, ${ }^{3}$ we found no significant association of hypertension, immunoglobulin abnormalities, or other clinical factors with retinal ischaemia. On the other hand we have shown that increased blood viscosity, platelet activation, and activation of blood coagulation exist in this group. If these factors play a causal role in capillary nonperfusion (by rheological obstruction, or occlusion by platelet-fibrin microthrombi), then reduction in blood viscosity, antiplatelet agents, or anticoagulants could have a place in the treatment of acute retinal vein occlusion, to prevent ischaemic complications.

The association of these blood abnormalities with ischaemic complications is not necessarily causal and may be consequential or coincidental. Since only a very small part of the total circulation is involved, it 
seems unlikely that the blood changes are the consequence of retinal ischaemia. Some workers have suggested that the ischaemic complications of retinal vein occlusion are due to arterial disease. ${ }^{24}$ Since increased blood viscosity, haematocrit, fibrinogen, factor VIII antigen and beta-thromboglobulin, and decreased platelet count have all been described in patients with arterial disease,$^{48}$ it is possible that their association with the ischaemic complications of retinal vein occlusion is coincidental-that is, both are associated with increased atherosclerosis.

Even if this is so, it is possible that it is the combination of poor arterial perfusion and increased blood viscosity and haemostasis which is important in predisposing an eye to ischaemia and neovascularisation. Further studies are required to determine whether the blood abnormalities are merely markers of vascular disease or whether they play a causal role in the ischaemic complications of retinal vein occlusion. The possibility that therapeutic alteration of the blood might prevent these complications is attractive, since there is no prophylactic therapy available at present.

We thank Dr S. Roxburgh, Mrs A. Rumley, Mrs M. McLaren, Mr P. Burns, and Mr. J. Anderson for their assistance with fluorescein angiography and laboratory tests.

This work is supported by the Frost Foundation (Dr Trope).

\section{References}

1 McGrath MA, Wechsler F, Hunyor ABL, Penny R. Systemic factors contributing to retinal vein occlusion. Arch Intern Med 1978; 138: 216-20.

2 Hume R, Begg IS. The relationship of blood volume and blood viscosity to retinal vessel size and circulation time in polycythaemia. In Cant JS, ed. The William McKenzie centenary symposium on the ocular circulation in health and disease. London: Kimpton, 1969: 158-69.

3 Ring CP. Pearson TC, Sanders MD, Wetherley-Mein G. Viscosity and retinal vein thrombosis. Br J Ophthalmol 1976; 60: 397-410.

4 Lowe GDO. Laboratory evaluation of hypercoagulability. Clin Haematol 1981; 10: 407-42.

5 Letcher RL, Chien S, Pickering TG, Sealey JE, Laragh JH. Direct relationship between blood pressure and blood viscosity in normal and hypertensive subjects. Role of fibrinogen and concentration. Am J Med 1981; 70: 1195-220.

6 Lowe GDO, McArdle BM, Stromberg P, Lorimer AR, Forbes $\mathrm{CD}$, Prentice CRM. Increased blood viscosity and fibrinolytic inhibitor in type II hyperlipoproteinaemia. Lancet 1982; i: 472-5. 7 Douglas JT, Shah M, Lowe GDO, Belch JJF, Forbes CD. Prentice CRM. Plasma fibrinopeptide $A$ and beta-thromboglobulin in pre-eclampsia and pregnancy hypertension. Thromb Haemostas 1982; 47: 54-5.

8 Lowe GDO. Forbes CD. Blood rheology and thrombosis. Clin Haematol 1981; 10: 343-67.

9 Lowe GDO, Campbell AF. Meek DR, Forbes CD, Prentice CRM, Cummings S. Subcutaneous ancrod in prevention of deep vein thrombosis after operation for fractured neck of femur. Lancet 1978; ii: 698-700.

10 Bowell RE, Marmion VJ, McCarthy CF. Treatment of central retinal vein thrombosis with ancrod. Lancet 1970; i: 173-4.

11 Kohner EM, Pettit JE, Hamilton AM, Bulpitt CJ, Dollery CT. Streptokinase in central retinal vein occlusion: a controlled clinical trial. Br Med J 1976; i: 550-3.

12 Wiederholt $M$. Hemodilution in retinal hypoperfusion. Bibl Haematol 1981; 47: 185-91.

13 Lowe GDO, Lowe JM, Drummond MM, et al. Blood viscosity in young male diabetics with and without retinopathy. Diabetologia 1980; 18: 359-63.

14 Kohner EM, Shilling JS. Retinal vein occlusion. In: Rose FC ed. Medical ophthalmology. London: Chapman and Hall, 1976: 391-429.

15 Peduzzi M, DeRosa V, Fonda S, Coccheri S. Haemostatic studies in retinal vein occlusion. Fibrinolytic response to venostasis as a prognostic factor for spontaneous recanalisation. Thromb Res 1981; 24: 105-18.

16 Thaler E, Lechner K. Antithrombin III deficiency and thromboembolism. Clin Haematol 1981; 10: 369-90.

17 Nossel HL, Yudelman I, Canfield RL, et al. Measurement of fibrinopeptide A in human blood. J. Clin Invest 1974; 54: 43-53.

18 Bensoussan D, Levy-Toledano S, Passa P, Caen J, Canivet J. Platelet hyper-aggregation and increased plasma level of von Willebrand factor in diabetics with retinopathy. Diabetologia 1975; 11: 307-12.

19 Tschopp TB, Weiss HJ, Baumgartner HR. Decreased adhesion of platelets to subendothelium in von Willebrand's disease. $J$ Lab Clin Med 1974; 83: 296-300.

20 Fuller JH, Keen H, Jarret RJ, et al. Haemostatic variables associated with diabetes and its complications. Br Med J 1979; ii: 964-6.

21 Schernthaner G, Sinzinger H. Silberbauer K, Freyler H, Mulhauser I, Kalinman J. Vascular prostacyclin, platelet sensitivity to prostaglandins and platelet-specific proteins in diabetes mellitus. In: Standl E, Mehnert H, eds. Pathogenetic concepts of diabetic microangiography. New York: Thieme, 1981: 33-43.

22 Walsh PN, Goldberg RE, Tax RL, Magargal LE. Platelet coagulant activities and retinal vein thrombosis. Thromb Haemostas 1977; 38: 399-406.

23 Priluck IA. Impending central retinal vein occlusion associated with increased platelet aggregability. Ann Ophthalmol 1979; 11: 79-85.

24 Hayreh SS, van Heuven WAJ, Hayreh MS. Experimental retinal vascular occlusion. I. Pathogenesis of central retinal vein occlusion. Arch Ophthalmol 1978; 96: 311-23. 